\title{
Sentinel lymph node biopsy in periocular merkel cell carcinoma: a case report
}

\author{
Dan C. Filitis ${ }^{1 *}$ (D) Gyorgy Paragh², Faramarz H. Samie ${ }^{3,1}$ and Nathalie C. Zeitouni ${ }^{4}$
}

\begin{abstract}
Background: The National Comprehensive Cancer Network guidelines for Merkel cell carcinoma recommend performance of the sentinel lymph node biopsy in all patients with clinically negative nodal disease for staging and treatment. Nevertheless, sentinel lymph node biopsy in the periocular region is debated as tumors are typically smaller and lymphatic variability can make performance procedurally problematic.
\end{abstract}

Case presentation: We present a case of a Caucasian patient in their seventies who presented with a $1.0 \mathrm{~cm}$ periocular Merkel cell carcinoma, who underwent Mohs surgery with a Tenzel flap repair, that was found to have a positive sentinel lymph node biopsy, but who, despite parotidectomy, selective neck dissection, and radiation, succumbed to the disease.

Conclusions: Evidence in both the site-specific and non-specific literature demonstrates: (1) Worsening prognosis with extent of lymph node burden, (2) improvements in our abilities to perform lymphoscintigraphy, (3) locoregional and distant metastatic disease in patients with tumor sizes $\leq 1 \mathrm{~cm}$, and (4) significant rates of sentinel lymph node positivity in patients with tumor sizes $\leq 1 \mathrm{~cm}$. Our case supports that sentinel lymph node biopsy should be considered in all clinically nodal negative periocular Merkel cell carcinoma, regardless of size, and despite limited site-specific studies on the subject.

Keywords: Merkel cell carcinoma, Periocular, Sentinel lymph node biopsy, Case report

\section{Background}

The sentinel lymph node biopsy (SLNB) plays an important role in the current staging and treatment of Merkel cell carcinoma (MCC) [1]. The National Comprehensive Cancer Network (NCCN) guidelines reflect this, recommending performance of the SLNB in all MCC patients that are clinically negative for nodal disease [2]. Still, whether all MCC patients are candidates for a SLNB, regardless of site of presentation or tumor characteristics, remains investigational and a matter of debate [3].

Periocular MCC represents anywhere from 5 to $20 \%$ of head and neck MCC $[4,5]$. This is a unique site with a high degree of lymphatic drainage variability where

\footnotetext{
*Correspondence: df2529@cumc.columbia.edu

1 Department of Dermatology, Columbia University Medical Center, 161

Fort Washington Avenue, 12th Floor, New York, NY 10032, USA

Full list of author information is available at the end of the article
}

tumors are often diagnosed earlier at smaller tumor sizes [6, 7]. Herein, we present a case of periocular MCC that highlights the aforementioned factors, and through review of the existing literature, aim to provide context for the decision to pursue SLNB at this distinctive site.

\section{Case presentation}

A Caucasian patient in their seventies with no personal or familial history of cutaneous malignancy presented with a biopsy-proven MCC, with angiolymphatic invasion of the right upper eyelid. Immunohistochemistry was positive for CK20 and negative for TTF-1. The patient underwent Mohs micrographic surgery and SLNB. At this time the small violaceous plaque measured $1.0 \times 0.8 \mathrm{~cm}$ and clinically and histologically residual MCC was noted in the tumor-debulking specimen. After two stages with negative margins, the final surgical defect measured 
$2.2 \times 0.8 \mathrm{~cm}$. The primary site was reconstructed with a Tenzel flap immediately following Mohs surgery. The SLN was positive for metastatic MCC and the patient thereafter underwent right superficial parotidectomy with facial nerve dissection and right selective neck dissection of levels 1-4. The parotid gland and all lymph nodes removed were negative for lymph node metastasis. Eight months after initial diagnosis the patient presented with multiple subdermal sub-centimeter masses palpable in the soft tissues of the right neck. Fine needle aspiration of a representative lesion was consistent with metastatic MCC. CT of the neck and chest with contrast identified diffuse metastatic disease affecting the lungs, liver, and the adrenals. The patient started palliative radiation for the right neck but succumbed to widespread metastatic disease 1 month later.

\section{Conclusions}

Periocular MCC is rare, and as such, literature and data are scarce. In fact, much of what we believe about the tumor's behavior and the role for SLNB at this site is extrapolated from MCC at other anatomic locations and data from other eyelid and conjunctival tumors.

Due to large variation in lymphatic drainage, higher rates of false negatives have been associated with SLNB in the head and neck region and the periocular region is no exception $[7,8]$. In the periocular region, previous false-negative values in studies looking at sebaceous carcinoma and melanoma ranged from 11 to $20 \%$ [9]. More recently however, rates of successful identification of SLN, on either pre- or intraoperative lymphoscintigraphy, were found to be as high as 97 and 100\%, respectively [10-13].

Site-nonspecific MCC studies report 11-57\% SLN positivity [1, 4, 14-25]. SLN positivity showed positive correlation with tumor size, tumor depth, mitotic rate, histological growth pattern, and presence lymphovascular invasion $[4,14-16]$. The literature on tumor factors associated with SLN positivity in periocular tumors is limited but trends suggest correlation of nodal metastasis with increased tumor size. In a recent study, 3 of 4 patients presenting with nodal metastasis were found to have $>$ T2b tumors at presentation, suggesting more nodal involvement with larger tumor size as has been demonstrated in the site-nonspecific literature [26].

Still, in comparison to MCC at other sites, for eyelid specific disease, performance of SNLB is seldom reported to date (Table 1). Amato et al. reported on a 61-year-old male with a right upper eyelid lesion that had a positive SLNB. Tumor characteristics were not provided [13]. Maalouf et al. [11] performed SLNB in 4 patients with periocular MCC, all with tumors $\leq 2 \mathrm{~cm}$, and found 1 of 4 to have a positive SLNB. One of the 3 patients with negative SLNB was defined as having had a falsely negative SLNB as they developed nodal disease 6 months after surgery. The median follow-up in that study was 18.7 months. Sneigowski et al. [26] performed SLN mapping in just 3 of 18 patients in their study-the demographics and tumor characteristics of which were not provided. Two of these patients had positive findings. Peters et al. reported performance of a SLNB in a

Table 1 Outcomes of sentinel lymph node biopsy in periocular merkel cell carcinoma

\begin{tabular}{|c|c|c|c|c|c|}
\hline Study & \# of patients & Age/gender & Tumor size & SLNB & Locoregional metastasis \\
\hline Amato et al. [13] & 1 & 61/male & NA & + & NA \\
\hline \multirow[t]{4}{*}{ Maalouf et al. [11] } & 4 & NA & $\leq 2 \mathrm{~cm}$ & + & NA \\
\hline & & & & - & Yes \\
\hline & & & & - & NA \\
\hline & & & & - & NA \\
\hline \multirow[t]{3}{*}{ Sniegowski et al. [26] } & 3 & NA & NA & + & NA \\
\hline & & & & + & NA \\
\hline & & & & - & NA \\
\hline \multirow[t]{3}{*}{ Peters et al. [27] } & 3 & 52/female & $1 \mathrm{~cm}$ & - & NA \\
\hline & & 96/male & $1 \mathrm{~cm}$ & NA & Yes \\
\hline & & 74/male & $0.6 \mathrm{~cm}$ & NA & Yes \\
\hline \multirow[t]{2}{*}{ Herbert et al. [28] } & 2 & $\mathrm{NA}$ & $<1 \mathrm{~cm}$ & - & NA \\
\hline & & 69/female & $0.8 \mathrm{~cm}$ & NA & Yes \\
\hline Esmaeli et al. [29] & 1 & 61/male & $1.2 \mathrm{~cm}$ & + & NA \\
\hline Kivelä et al. [5] & 1 & 79/female & $0.8 \mathrm{~cm}$ & NA & Yes \\
\hline Filitis et al. ${ }^{*}$ & 1 & seventies/NA & $1 \mathrm{~cm}$ & + & Yes \\
\hline
\end{tabular}

NA not available/reported/performed

* current study 
52-year-old woman with $1 \mathrm{~cm}$-sized lesion on the left upper eyelid. This was found to be negative [27]. Herbert et al. [28] reported performance of a SLNB in just 1 patient of their 21 . Tumor size at presentation was $<1 \mathrm{~cm}$, and the results of SNLB were negative. Finally, Esmaeli et al. [29] reported a positive SLNB in a 61-year-old man with a $1.2 \mathrm{~cm}$ lesion on the left upper eyelid.

Some of these same studies report regional nodal and metastatic spread tends to be lower than at other sites at around 19-22\% [26-28]. Some authors speculate that decreased tumor size at presentation may explain these lower reported rates of nodal metastasis [30]. Site-associated variation in lesion size has been previously demonstrated and some authors have attributed it to earlier detection. Yin et al. [6] speculate that earlier detection in eyelid disease specifically may be due to better visualization and perhaps related to visual field impedance, as that would be difficult to disregard. In a study by Allen et al. [22] the authors showed that the head and neck region, compared to other sites, demonstrates significantly smaller tumor diameters, as well as decreased clinically apparent nodal disease. Taken together, site associated tumor size and trends between size and SLN positivity may explain the decreased nodal metastatic potential seen in some periocular disease.

Even smaller MCC carry a significant risk of locoregional disease spread. For example, Schwartz et al. demonstrated SLNB positivity rates of $23 \%$ in tumor sizes $\leq 1 \mathrm{~cm}$, while Fields et al. showed a similar $26 \%$ SLN positivity at $\leq 1 \mathrm{~cm}$ tumor size, and Iyer et al. demonstrated $14 \%$ nodal involvement for $0.5 \mathrm{~cm}$ tumors [1416]. In other cutaneous malignancies a threshold of $10 \%$ nodal positivity is widely used to justify performance of SLNB [4]. To date, the overwhelming majority of studies looking at SLN positivity in MCC demonstrate SNL positivity rates above this threshold, even in small tumors.

Cases reported in the periocular-specific MCC literature demonstrate regional nodal and/or distant metastatic disease at tumor sizes $\leq 1 \mathrm{~cm}[5,27,28]$ (Table 1). Kivelä et al. reported a case of a 79-year-old female with a $0.8 \mathrm{~cm}$ tumor that developed regional nodal metastasis approximately 6 months after biopsy and radiation [5]. Peters et al. reported 2 cases with tumor sizes $\leq 1 \mathrm{~cm}$ that went on to have nodal metastasis; one, a 96-year-old male, who developed ipsilateral submandibular node involvement 2.5 years after Mohs with $3 \mathrm{~mm}$ margins for a $1 \mathrm{~cm}$ left canthus lesion, and two, a 74-year-old male who developed ipsilateral parotid gland recurrence after $12 \mathrm{~mm}$ wide excision of a $4 \times 6 \mathrm{~mm}$ right upper eyelid lesion [27]. Herbert et al. reported a 69-year-old female who presented with $8 \mathrm{~mm}$ eyelid lesion that developed both regional metastasis to the parotid nodes and distant metastasis to the chest 6 months after wide local excision. [28].
The case we present further exhibits the unpredictability of clinical outcomes with small periocular MCC-presenting at $1.0 \mathrm{~cm}$ on the right upper eyelid. Performance of lymphoscintigraphy and SLNB, as seen in our case, demonstrates how SNL positivity can be a helpful towards understanding the severity of one's disease and justifying additional intervention. To this end, in the recent past, Iyer et al. [14] demonstrated that more extensive lymph node involvement is correlated with decreased survival, and just this past year, taking advantage of the tumor's programmed-death-ligand-1 (PD-L1) expression, a report showed a $56 \%$ objective response rate when patients with advanced MCC were treated with pembrolizumab [31]. In March 2017, the United States Food and Drug Administration (FDA) granted accelerated approval of avelumab, an anti-PD-L1 antibody and the first FDA-approved medication to treat metastatic MCC [32]. With the advent of immunotherapy early accurate risk assessment may translate into better survival even if this has previously only been a distant mirage.

Evidence clearly outlining a role for SLNB in periocular $\mathrm{MCC}$ is largely lacking, nevertheless, implications from the general MCC literature, periocular-specific studies, and case reports such as ours, are relevant and worth consideration. Collectively, this data, and now the development of new, risk-stratified, treatment options help explain why multiple authors, ourselves included, continue to advocate that SLNB be strongly considered, [33] if not recommended, [30] for all periocular MCC and regardless of size.

\section{Abbreviations}

MCC: Merkel cell carcinoma; NCCN: National Comprehensive Cancer Network; PD-L1: programmed death ligand 1; SLN: sentinel lymph node; SLNB: sentinel lymph node biopsy; FDA: Food and Drug Administration.

\section{Authors' contributions}

All authors read and approved the final manuscript.

\section{Author details}

${ }^{1}$ Department of Dermatology, Columbia University Medical Center, 161 Fort Washington Avenue, 12th Floor, New York, NY 10032, USA. ${ }^{2}$ Department of Dermatology, Department of Cell Stress Biology, Roswell Park Cancer Institute, Buffalo, USA. ${ }^{3}$ Columbia University Medical Center, New York, USA.

${ }^{4}$ University of Arizona COM Phoenix, University of Arizona Cancer Center at Dignity Health, 625 N 6th Street, Phoenix, AZ 85004, USA.

\section{Acknowledgements}

Not applicable.

Competing interests

The authors declare that they have no competing interests.

Availability of data and materials

Not applicable.

Ethics approval and consent to participate Not applicable. 


\section{Consent for publication}

Written informed consent for publication could not be obtained despite all reasonable attempts at contacting our deceased patient's next of kin. Every effort has been made to protect the identity of our patient.

\section{Funding}

Not applicable.

\section{Publisher's Note}

Springer Nature remains neutral with regard to jurisdictional claims in published maps and institutional affiliations.

Received: 10 November 2016 Accepted: 21 August 2017

Published online: 20 September 2017

\section{References}

1. Gupta SG, Wang LC, Peñas PF, Gellenthin M, et al. Sentinel lymph node biopsy for evaluation and treatment of patients with Merkel cell carcinoma: the Dana-Farber experience and meta-analysis of the literature. Arch Dermatol. 2006;142(6):685-90.

2. National Comprehensive Cancer Network [NCCN]. NCCN Clinical practice guidelines in oncology. http://www.nccn.org/professionals/physician_ gls/f_guidelines.asp.

3. Stokes JB, Graw KS, Dengel LT, et al. Patients with Merkel cell carcinoma tumors $<$ or $=1.0 \mathrm{~cm}$ in diameter are unlikely to harbor regional lymph node metastasis. J Clin Oncol. 2009;27(23):3772-7.

4. Smith FO, Yue B, Marzban SS, Walls BL, et al. Both tumor depth and diameter are predictive of sentinel lymph node status and survival in Merkel cell carcinoma. Cancer. 2015:121(18):3252-60.

5. Kivelä T, Tarkkanen A. The Merkel cell and associated neoplasms in the eyelids and periocular region. Surv Ophthalmol. 1990;35(3):171-87.

6. Yin VT, Merritt HA, Sniegowski M, Esmaeli B. Eyelid and ocular surface carcinoma: diagnosis and management. Clin Dermatol. 2015;33(2):159-69.

7. Nijhawan N, Marriott C, Harvey JT. Lymphatic drainage patterns of the human eyelid: assessed by lymphoscintigraphy. Ophthal Plast Reconstr Surg. 2010;26(4):281-5.

8. Willis Al, Ridge JA. Discordant lymphatic drainage patterns revealed by serial lymphoscintigraphy in cutaneous head and neck malignancies. Head Neck. 2007;29(11):979-85.

9. Ho VH, Ross MI, Prieto VG, Khaleeq A, et al. Sentinel lymph node biopsy for sebaceous cell carcinoma and melanoma of the ocular adnexa. Arch Otolaryngol Head Neck Surg. 2007;133(8):820-6.

10. Savar A, Ross MI, Prieto VG, Ivan D, et al. Sentinel lymph node biopsy for ocular adnexal melanoma: experience in 30 patients. Ophthalmology. 2009;116(11):2217-23.

11. MaaloufTJ, Dolivet G, Angioi KS, Leroux A, et al. Sentinel lymph node biopsy in patients with conjunctival and eyelid cancers: experience in 17 patients. Ophthal Plast Reconstr Surg. 2012;28(1):30-4.

12. Echegoyen JC, Hirabayashi KE, Lin KY, Tao JP. Imaging of eyelid lymphatic drainage. Saudi J Ophthalmol. 2012;26(4):441-3.

13. Amato M, Esmaeli B, Ahmadi MA, et al. Feasibility of preoperative lymphoscintigraphy for identification of sentinel lymph nodes in patients with conjunctival and periocular skin malignancies. Ophthal Plast Reconstr Surg. 2003;19(2):102-6.

14. Iyer JG, Storer BE, Paulson KG, Lemos B, et al. Relationships among primary tumor size, number of involved nodes, and survival for 8044 cases of Merkel cell carcinoma. J Am Acad Dermatol. 2014;70(4):637-43.
15. Schwartz JL, Griffith KA, Lowe L, Wong SL, et al. Features predicting sentinel lymph node positivity in Merkel cell carcinoma. J Clin Oncol. 2011;29(8):1036-41.

16. Fields RC, Busam KJ, Chou JF, Panageas KS, et al. Recurrence and survival in patients undergoing sentinel lymph node biopsy for Merkel cell carcinoma: analysis of 153 patients from a single institution. Ann Surg Oncol. 2011;18(9):2529-37.

17. Sarnaik AA, Zager JS, Cox LE, Ochoa TM, et al. Routine omission of sentinel lymph node biopsy for Merkel cell carcinoma $<=1 \mathrm{~cm}$ is not justified. J Clin Oncol. 2010;28(1):e7.

18. Lemos BD, Storer BE, Iyer JG, Phillips JL, et al. Pathologic nodal evaluation improves prognostic accuracy in Merkel cell carcinoma: analysis of 5823 cases as the basis of the first consensus staging system. J Am Acad Dermatol. 2010;63(5):751-61.

19. Shnayder Y, Weed DT, Arnold DJ, Gomez-Fernandez C, et al. Management of the neck in Merkel cell carcinoma of the head and neck: University of Miami experience. Head Neck. 2008;30(12):1559-65.

20. Warner RE, Quinn MJ, Hruby G, Scolyer RA, et al. Management of Merkel cell carcinoma: the roles of lymphoscintigraphy, sentinel lymph node biopsy and adjuvant radiotherapy. Ann Surg Oncol. 2008;15(9):2509-18.

21. Maza S, Trefzer U, Hofmann M, Schneider S, et al. Impact of sentinel lymph node biopsy in patients with Merkel cell carcinoma: results of a prospective study and review of the literature. Eur J Nucl Med Mol Imaging. 2006;33(4):433-40.

22. Allen PJ, Bowne WB, Jaques DP, Brennan MF, et al. Merkel cell carcinoma: prognosis and treatment of patients from a single institution. J Clin Oncol. 2005:23(10):2300-9.

23. Mehrany K, Otley CC, Weenig RH, Phillips PK, et al. A meta-analysis of the prognostic significance of sentinel lymph node status in Merkel cell carcinoma. Dermatol Surg. 2002;28(2):113-7 (discussion 117).

24. Hill AD, Brady MS, Coit DG. Intraoperative lymphatic mapping and sentinel lymph node biopsy for Merkel cell carcinoma. Br J Surg. 1999:86(4):518-21.

25. Messina JL, Reintgen DS, Cruse CW, Rappaport DP, et al. Selective lymphadenectomy in patients with Merkel cell [cutaneous neuroendocrine] carcinoma. Ann Surg Oncol. 1997;4(5):389-95.

26. Sniegowski MC, Warneke CL, Morrison WH, Nasser QJ, et al. Correlation of American Joint Committee on Cancer T category for eyelid carcinoma with outcomes in patients with periocular Merkel cell carcinoma. Ophthal Plast Reconstr Surg. 2014:30(6):480-5.

27. Peters GB 3rd, Meyer DR, Shields JA, Custer PL, et al. Management and prognosis of Merkel cell carcinoma of the eyelid. Ophthalmology. 2001;108(9):1575-9.

28. Herbert HM, Sun MT, Selva D, Fernando B, et al. Merkel cell carcinoma of the eyelid: management and prognosis. JAMA Ophthalmol. 2014;132(2):197-204.

29. Esmaeli B, Naderi A, Hidaji L, Blumenschein G, Prieto VG. Merkel cell carcinoma of the eyelid with a positive sentinel node. Arch Ophthalmol. 2002;120(5):646-8.

30. Pfeiffer ML, Savar A, Esmaeli B. Sentinel lymph node biopsy for eyelid and conjunctival tumors: what have we learned in the past decade? Ophthal Plast Reconstr Surg. 2013;29(1):57-62.

31. Nghiem PT, Bhatia S, Lipson EJ, Kudchadkar RR, et al. PD-1 Blockade with pembrolizumab in advanced Merkel-cell carcinoma. N Engl J Med. 2016:374:2542-52.

32. US Food and Drug Administration. 2017. Approved Drugs. https://www fda.gov/Drugs/InformationOnDrugs/ApprovedDrugs/ucm547965.htm. Accessed 10 May 2017

33. Merritt H, Sniegowski MC, Esmaeli B. Merkel cell carcinoma of the eyelid and periocular region. Cancers [Basel]. 2014;6(2):1128-37. 